\title{
Adaptation of Graduates and Students of Regions to Education in Higher Education Institutions of Russia by Means of Social-Psychological Training
}

\author{
Bogdan Vasyakin $^{1}$, Maria Berezhnaya ${ }^{1}$, Elena Pozharskaya ${ }^{1} \&$ Nelia Deberdeeva ${ }^{1}$ \\ ${ }^{1}$ Department of psychology, Russian Economical University named after Plekhanov G.V., Moscow, Russian \\ Federation \\ Correspondence: Vasyakin Bogdan Sergeevich, department of psychology, Russian Economical University \\ named after Plekhanov G. V., Stremyanny side street, building 36, Moscow, Russian Federation.
}

Received: December 20, 2014

Accepted: January 5, 2015 Online Published: February 25, 2015

doi:10.5539/res.v7n3p88

URL: http://dx.doi.org/10.5539/res.v7n3p88

\begin{abstract}
One of the important tasks of educational system of higher educational institutions is the performance of continuous work aimed at successful social-psychological adaptation to the new system of education and social relationships of students of first years of learning. The aim of this paper, with due account of available experience of adaptation of students to the new system of education and also on the basis of results of research conducted by authors, is to develop optimal model of student's social-psychological adaptation to new educational environment, in the process of which there is personal development of educate and the environment itself. The research conducted by the authors of this paper presents practical significance for development and implementation of theoretical and methodological model of psychological student school for the purpose of development of socio-cultural adaptation opportunities of students, particularly in the regions Russian Federation.
\end{abstract}

Keywords: social-psychological adaptation, social-psychological training, integration, socio-cultural adaptation, social role, value orientation, cooperation, communicative culture

\section{Introduction}

The change of social situation for development, in which there is a graduate taking the status of student of higher educational institution, his modifying social role, restructuring of personal and value orientations as well as the relationships with persons he is to cooperate with - these and other factors have significant influence on social-psychological adaptation of graduates and students to education in economical universities of Russia.

The active transformation of habitual way of living of young people challenge them for absolute readiness for acceptance and realization of current changes and the ability quickly, adequately and timely to respond to them by means of actualization of internal resources (Rean, 1995).

The scientific novelty of considering problem covers the following aspects:

○ We suggest theoretical justifications for classification of four strategies for students' adaptation behavior in higher educational institution (the active change of environment, personal changes, non-resistance to the conditions of the environment, passive plunge into own inner world) depending on the stage of adaptive process.

$\circ$ There is an optimal model of social-psychological adaptation of student, as the process of cooperation of subjects of equal right - the student and the educational environment, in the course of which there is a development of the person and the environment.

- We have developed the diagnostic instruments for definition of strategies for student's adaptation behavior upon the conditions of development of student's self-government (SSG).

o The interrelation between the structure of students' social values and the efficiency of SSG activities is defined.

○ The connection of using distinct strategies for students' adaptation behavior depending on the stage of adaptation is defined. 
○ The role of SSG in formation of student's adaptation behavior is defined and proven.

In the higher educational institutions of Russia various forms of working on activation of process of transition of school leavers and graduates to the status of student of HEI are implemented. Definite work in this direction is already held in the Russian Economical University (REU) named after Plekhanov G.V. Here, taking into consideration the new circumstances linked to the entering and studying in university of seniors (graduates) and students of Crimea and Sevastopol, the psychological student school under the department of Psychology was found. The school functions within the frameworks of the grant on performance of scientific and research works together with the group of young scientists on the subject of "The integration of the program for socio-cultural and psychological adaptation of seniors (to-be-graduates) and students of Crimea and Sevastopol to education in economical universities of Russia into the educational system" (decree No. 647 of July 29, 2014).

\subsection{Literature Review}

In the recent years there is significant evolution in understanding the phenomenon of social-psychological adaptation (including the adaptation in the sphere of education) that is characterized with the following tendencies: the increasing differentiation of the "adjusting" and "adaptation" concepts; the transition from passive adaptation to construction of the system of effective interaction between a person and the environment; and from the ultimate goal of homeostatic equilibrium and absence of conflicts to the ultimate goal of self-actualization and self-realization of a person in real social environment (Abulkhanova-Slavskaya, Ball, Parygin, Rean, Nachaldjyan).

Vachkov, I. V. states that training is the method of work, in the frameworks of which a psychologist should not only assist in solving existing problems of participators, but also render treatment by affording opportunity of "learning how to solve the problems" (Vachkov, 2011).

Russian scientists point out three blocks of factors that influence on adaptation to education in university: sociological, psychological and pedagogic ones. Under the term of "factor" within the present context we should consider the moment or significant circumstance in the process, internal cause, driving force in some process or phenomenon defining its character or distinct features. In return, the factors can be external and internal. The external factors cover sociological block (age, social status, type of pre-university education) and pedagogical block (organization of the environment, material and technical base of institution, the level of professors' art of teaching). The internal factors cover psychological block that includes individual psychological and social-psychological (orientation, intellect, motivation, personal adaptational potential of first-year student) factors (Milkovskaya \& Bezuleva, 2008).

The list of the factors influencing the process of students' adaptation to education in HEI is added and enlarged by Khitskaya V. Y. She has combined them into four groups. The first group covers the factors that reflect the level of preparation of graduates for educational activities in university: the volume and level of their knowledge, their professional orientation, demand of graduates for educational activities (Khitskaya, 2008). This group of factors is directly related to the problematics, which is solved by psychological student school under the department of psychology of the Russian Economical University named after Plekhanov G. V. (hereinafter referred to as "the University").

In accordance with the specified subject the school holds work in several directions:

- Performs diagnostics with identifying of personal characteristics of graduates and students of the University and problems of adaptation to culture of the University;

- Plans and performs the work on psycho-correctional and developing influence on student's personality designed for release from any problems of psychological character, correction of behavior and improvement of the level of social-psychological adaptation;

- Develops and realizes training programs for adaptation of first-year students to the corporate culture of the University;

- Conducts training affairs aimed at the development of personal qualities and skills of students as future specialists, executives;

- Develops and conducts trainings on formation of effective business communications, skills of efficient presentations, setting of goals and career growth, activation of adaptive reactions of organism, achieving emotional well-being, teaching students for use of socially-acceptable methods for relaxation of emotional and muscular tension. 
Students being an integral part of youth presents specific social group that is characterized with special conditions of living, working and everyday activities, social behavior and psychology, the system of value orientations. Rural students present special group in terms of achievement of personhood (Dikaya \& Zhuravlev, 2007).

Resting on the scientific conclusions of Russian and foreign scientists and proceeding from specified directions of work, the school should solve one of the main tasks: the development of socio-cultural adaptation opportunities of studying students of Crimea and Sevastopol within the process of integration into united Russian-Ukrainian mentality and the program of its realization including the set of training programs for the purpose of development of communicative skills and social-psychological characteristics of students' personalities and also of adaptational social-psychological characteristics of personalities of students and graduates.

The specialists of psychological school have developed and approved the social-psychological training aimed at the development of communicative skills and social-psychological characteristics of personalities of students, reduction of the conflict level, increase of cohesion of collective and also of adaptational social-psychological characteristics of personalities of first-year students for education in economical universities of Russia. In addition, the program for socio-cultural and psychological adaptation of students of Crimea and Sevastopol to education in economical universities of Russia covers the work on research of influence of social-psychological training on adaptation of first-year students to education and is aimed at optimization of processes of their business and interpersonal communication. The designed and approved program of the training is being appropriate for the optimization of the processes of business communication in groups of first-year students and, subsequently, for increase of adaptational social-psychological characteristics of personalities of students and graduates.

Despite the fact that different authors suggest own types of trainings classifications, program of trainings is, as a rule, designed in such a way it includes elements of different types of training. In our situation the training is focused on the development of communicative skills, in particular, in such a sphere of communication as interaction that implies construction of common strategy for cooperation between studying individuals, i.e. the exchange not only of knowledge and ideas, but also of actions. The main tasks of our training are teaching of students for skills and abilities of communication (interaction), creation of conditions that would promote the development of personality, increase of social-psychological competence of participants, formation of their active social position, development of ability adequately and fully to cognize themselves and other people within the process of communication. Besides, the task of trainings is the correction of abilities, raise the barriers preventing students from effective process of education and also research and mastering individualized methods for interpersonal cooperation for increase of its efficiency and, subsequently, increase of adaptational social-psychological characteristics of personalities of students and graduates.

To introduce changes into the training, which are being the result of interiorization of models of behaviour and activity presented in it by means of their realization and including in cognitive and regulative structures of psyche in the form of skills, abilities and settings, it is necessary to create within the training the specific environment accounting for the needs of reality and creating informational load on psychological features and formations subject to change. Herewith, we should take into consideration the fact that psychological formations occurring within the process of interiorization of external context that is created in the training activate self-correction, self-development and, subsequently, cause their activity.

The including in the training program of definite exercises and use of definite procedures (such as "empathetic audition" exercise) allows better understanding of partner's intention, his positions and status as well as improving cooperation with him along with minimization of some communicative barriers. The "Image of group" exercise and reflexion of exercises allow realizing own emotional states, ways of behaviour, self-determination of status, stereotypes, own and partner's effects of interpersonal perception. This helps consciously to build the structure of a group, role relations, interaction patterns and also to create the most effective relation scheme that promotes increase of cohesion and, subsequently, of adaptation in a student group.

We can also consider the process of social and psychological adaptation through the joint activity in the frameworks of group processes, where there is continuous influence of people on each other with subsequent change of oneself and other ones.

The exercise for "Communication under conditions of different cultures" and "Unison" exercise promote identifying stereotypes, realization of positions (partner's and own), conditions of situation, special interpretation, perception and orientation of partners that allows constructing new forms of cooperation. 
The formation of value orientations complex is possible only under conditions of organized educational process. As Kantor V. Z. mentions "the complex of value orientations and axiological potential of personality should form just under conditions of organized educational process" (Bezuleva, 2008).

Such a position is also in the picture of conducted research that had initially implied pre-training and post-training diagnostics in experimental and control groups and, peculiarly, in conduction of training in experimental group. The participators of research are presented with 9 students of REU named after Plekhanov G.V. in the age of 17-18 from Crimea and Sevastopol and 9 more first-year students from the Moscow region. The pre-training and post-training testing was holding with use of questionaries: the test for description of behaviour by Thomas K., the test of "Communicative and organizational tendencies" (COT-2), three questionaries of Amyaga N.V. and methods of "group self-conception" consisting of two parts. The practices were held in the groups for two times: several days prior to the beginning of training lessons and at the end of the last day of training lessons. The training of active group psychological impact was held only in experimental group.

The organization of pre-test and post-test in experimental and control groups was performed under one scheme.

Thus, in each of the groups there were two quizzes obtained, the analysis of which allows evaluating the effectiveness of training procedure.

The whole training cycle was meant for fourteen academic hours. The training had been lasted for four weeks with meetings held once a week. The duration of the first meeting made up two academic hours, the rest of the meetings had been lasted for four academic hours. The lessons were held in the building of REU named after Plekhanov G. V.

Virtually the research was divided into 3 stages:

Stage I: the pre-testing.

The stage of pre-testing preparation and the conduction of interview with supposed participators of the training.

At this stage the diagnostics of two groups for the effectiveness of business communication and the proneness of participators to conflict behaviour was conducted.

Stage II: the training.

The conduction of developed psychological training aimed at increase of cohesion of collective, reduction of conflict level, improvement of communication quality.

Surveillance over the behaviour of participators of the training and arising changes, analysis of oral reports of participators of the training at the end of the lesson.

Stage III: the post-training testing.

Conduction of repeated diagnostics in experimental and control groups for the purpose of identification of the changes that had taken place in the course of active group psychological impact.

\section{Materials and Methods}

The main methods of research were the tests of effective business communication in group, proneness to conflict behaviour and interpersonal conflicts. These tests are the test for description of behaviour designed by Thomas $\mathrm{K}$. adapted for studying personal proneness to conflict behaviour by Grishina, N. V. and the test of "communicative and organizational tendencies" (COT-2) aimed at identification of "communicative and organizational tendencies". In addition, several questionaries were used. They are: "Measurement of personal representativeness of a man in communication. The questionary for the ability to control self-presentation in communication" (QACSC) designed by Amyaga, N. V. and aimed at measurement of the degree of person's ability to control his behaviour; "Measurement of personal representativeness of a man in communication. The questionary for the ability to cause the frankness of conversation partner" (QACFCP) designed by Amyaga N. V. for diagnostics of the ability to draw out the communication partner for frankness"; "Measurement of personal representativeness of a man in communication. The questionary for the level of self-disclosure" (QLS) designed by Amyaga N. V. for identification of person's ability to self-disclose and being modification of questionary of Jourard S. (the present methods were chosen in accordance with ideas implying that setting up of successful cooperation is defined with person's availability of two balanced tendencies: "openness" and "interest towards the personality of other man").

Another one method was "The method of group self-conception" consisting of two parts:

a) The first part-nine bipolar scales of quality that allow measuring the effectiveness of training procedure 
through change of self-perception and subjective estimation of oneself;

b) The second part implies making by group the list of qualities important for the process of business communication and their ranging. It was used for tracking the dynamics of change of group ideas about qualities that promote the communication process and also as the additional monitoring instrument. The analysis on surveillance over the group was conducted in accordance with "expert list" drawn up on the basis of analysis of literature and including twenty one qualities preventing or promoting the process of business communication.

Another one method used was the psychological method of "conversation", in the course of which collection of requests in respect of expected training results was held.

The central element of the research is being the training for increase of cohesion of collective, reduction of level of conflicts and improvement of communication quality. In social context the psychological training was organized in accordance with the principles of the systematic formation theory, the overall structure of which included three parts: psychological diagnostics (pre-testing); training; diagnostics (post-testing). In such a case the control should not be limited with resulting post-testing. On the contrary - it should be added with intermediate control or the control on process, the role of which in our situation is played with reflexion of every exercise, while the obtained results should be used for correction of educational process and introducing necessary changes. The training is divided into two key parts: orientating one - when information necessary for solving the task is distinguished; it promotes not only correct performance of action, but also the rational choice of one of the majority of possible performances. A person, who performs orientating part of an action, relies upon the orientating basis of the action (OBA) and the performing part, in which there is solution of the task itself. In the present case OBA was drawn up for the purpose of increase of competence within the process of communication between participators of training and is presented with number of questions aimed at the analysis of the situation of cooperation within communication from the perspectives of "competence in oneself", "competence in partner" and "competence in situation".

The exercises made up the training program were selected in the way to provide competence in communication as integrative characteristic that realizes by means of introduction of three aspects of communication to it (see Table 1).

Table 1. The list of forming exercises with correspondent characteristics of skills

\begin{tabular}{|c|c|c|}
\hline Exercise & Competence & Skills, aspects of communication \\
\hline $\begin{array}{ll}\text { Test } & \text { with } \\
\text { implication } & \end{array}$ & $\begin{array}{l}\text { In situation, in } \\
\text { oneself }\end{array}$ & Attention, orientation in situation, mutual understanding \\
\hline Unison & $\begin{array}{l}\text { In situation, in } \\
\text { oneself, in partner }\end{array}$ & $\begin{array}{l}\text { Mutual understanding, cooperation, the ability to adapt, emphasis } \\
\text { on reading of "non-verbalics", roles, positions, self-presentations, } \\
\text { style of cooperation, identification with partner in communication, } \\
\text { sensitivity. }\end{array}$ \\
\hline Penalty & $\begin{array}{l}\text { In situation, in } \\
\text { oneself, in partner }\end{array}$ & $\begin{array}{l}\text { The ability to agree on smth. and come to a compromise, mutual } \\
\text { understanding, interpretations of partner's behaviour, roles, } \\
\text { statuses, positions, behaviour, types of cooperation, group pressure, } \\
\text { effects of perception, stereotypes, identification with partner in } \\
\text { communication, sensitivity, interaction, communication. }\end{array}$ \\
\hline $\begin{array}{l}\text { Communication } \\
\text { under condition of } \\
\text { different cultures }\end{array}$ & $\begin{array}{l}\text { In situation, in } \\
\text { oneself, in partner }\end{array}$ & $\begin{array}{l}\text { Assertive behaviour, mutual understanding, interperception, } \\
\text { interevaluation, types of cooperation, realization of behaviour of } \\
\text { partners in communication, mutual influence, effects of recency } \\
\text { primacy and halo, causal attribution, interaction, perception, } \\
\text { communication. }\end{array}$ \\
\hline Active listening & $\begin{array}{l}\text { In situation, in } \\
\text { oneself, in partner }\end{array}$ & $\begin{array}{l}\text { Interaction, communication, perception, feeling of partner's state, } \\
\text { setting of cooperation with account of partner's position, the ability } \\
\text { to agree on smth., minimization of communicative barriers, mutual } \\
\text { help. }\end{array}$ \\
\hline
\end{tabular}




\begin{tabular}{|c|c|c|}
\hline Exercise & Competence & Skills, aspects of communication \\
\hline Image of group & $\begin{array}{l}\text { In situation, in } \\
\text { oneself, in partner }\end{array}$ & $\begin{array}{l}\text { Perception, communication, cooperation, mutual evaluation and } \\
\text { self-conception, mutual perception and self-perception, perception } \\
\text { of situation and orientation in it, effects of polarization, } \\
\text { normalization and shift to risk, role characteristics, behaviour of } \\
\text { partners, their positions, statuses. }\end{array}$ \\
\hline $\begin{array}{l}\text { Hello! I am an } \\
\text { audile }\end{array}$ & $\begin{array}{l}\text { In situation, in } \\
\text { oneself, in partner }\end{array}$ & $\begin{array}{l}\text { Interaction, perception and communication, identification of } \\
\text { partner's modality, harmonization with partner that promotes } \\
\text { speaking a common language, mutual understanding, minimization } \\
\text { of communicative barriers, feedback. }\end{array}$ \\
\hline Reflexion & $\begin{array}{l}\text { In oneself, in } \\
\text { situation }\end{array}$ & $\begin{array}{l}\text { The perception of oneself through the perception of other one, } \\
\text { perception of oneself through the results of personal activity, } \\
\text { correction of subsequent behaviour and style of cooperation, mutual } \\
\text { help. }\end{array}$ \\
\hline $\begin{array}{l}\text { Group } \\
\text { decision-making }\end{array}$ & $\begin{array}{ll}\text { In oneself, in } \\
\text { partner, } & \text { in } \\
\text { situation } & \end{array}$ & $\begin{array}{l}\text { Organization of joint activity, communication, perception, } \\
\text { interaction, effects of normalization, risk shift, polarization, group } \\
\text { pressure, conformity, group cohesion, understanding of partner, } \\
\text { harmonization with partner, mutual evaluation, mutual } \\
\text { understanding, interperception, stereotypes, halo effect, recency } \\
\text { effect, causal attribution, empathy, sensitivity, effect of sanctions } \\
\text { and norms. }\end{array}$ \\
\hline
\end{tabular}

\section{Results}

The conducted post-training examination in experimental and control groups showed that the training had significant impact on experimental group, while in the control group there was no dynamic of indicators registered (see Table 2).

The character of interaction between members of experimental group in the post-testing demonstrated the strategy for cooperation. It manifested itself in aspiration of participators to meet the needs of each other, come to an alternative fully complied with the interests of parties. At the same time the interaction was organized with account of partner's position and conditions of situation, what can witness the increase of competence in communication.

Table 2. Communicative skills before and after training in referential and control groups

\begin{tabular}{llllllll}
\hline $\begin{array}{l}\text { Referential group before } \\
\text { training }\end{array}$ & $\begin{array}{l}\text { Referential } \\
\text { training }\end{array}$ & group after & $\begin{array}{l}\text { Control group before } \\
\text { training }\end{array}$ & $\begin{array}{l}\text { Control group after } \\
\text { training }\end{array}$ & group \\
\hline 12.4 & 17.8 & & 11.8 & & 12.1 & \\
\hline
\end{tabular}

As we can see from Table 2, according to data of COT-2, communicative skills in the main, experimental, group have reliably increased from $12.4 \pm 0.7$ to $17.8 \pm 0.46$. In the control group there was no reliable dynamics registered $(11.8 \pm 0.82$ and $12.1 \pm 0.83)$.

There is also improvement of organizational skills (see Table 3). Since the questions of COT-2 test imply personal orientation of respondent, the improvement of results in experimental group after conduction of training can be explained with the change of personal attitude of the majority of participators of the training. After training they began to perceive own predispositions in more optimistic way and, probably, even reconsidered some interpretations of their behaviour. 
Table 3. Organizational skills before and after training in referential and control groups

\begin{tabular}{llllllll}
\hline $\begin{array}{l}\text { Referential group before } \\
\text { training }\end{array}$ & $\begin{array}{l}\text { Referential } \\
\text { training }\end{array}$ & group after & $\begin{array}{l}\text { Control group before } \\
\text { training }\end{array}$ & $\begin{array}{l}\text { Control group after } \\
\text { training }\end{array}$ & gran \\
\hline 11.4 & 17.6 & 11.2 & & 11.4 & \\
\hline
\end{tabular}

According to the results of re-conducted test of Thomas K., there is significant dynamics in predisposition to cooperation (from 5,4 $\pm 0,64$ to $9,1 \pm 0,65$ ) and compromise (from 5,8 $\pm 0,41$ to 9,7 $\pm 0,62$ ), (see Table 4).

Table 4. Cooperation and readiness for compromise before and after training

\begin{tabular}{lllllllll}
\hline $\begin{array}{l}\text { Referential group before } \\
\text { training }\end{array}$ & $\begin{array}{l}\text { Referential group after } \\
\text { training }\end{array}$ & $\begin{array}{l}\text { Control } \\
\text { training }\end{array}$ & group before & $\begin{array}{l}\text { Control } \\
\text { training }\end{array}$ & group after \\
\hline
\end{tabular}

Cooperation
5.4
9.1
6.0
5.9

Readiness for compromise
5.8
9.7
6.2
6.3

The increase of predisposition to cooperation and compromise in the main group is explained only with the impact of the training, for in the control group there was no dynamics in the same parameters registered.

Predisposition to rivalry, according to the data of test of Thomas, has slightly reduced in the main group after training (see Table 5).

Table 5. The rivalry in referential and control groups before and after training

\begin{tabular}{llllllll}
\hline $\begin{array}{l}\text { Referential group before } \\
\text { training }\end{array}$ & $\begin{array}{l}\text { Referential group } \\
\text { training }\end{array}$ & after & $\begin{array}{l}\text { Control group before } \\
\text { training }\end{array}$ & $\begin{array}{l}\text { Control group after } \\
\text { training }\end{array}$ & group \\
\hline 8.0 & 7.6 & 8.2 & & 8.3 & \\
\hline
\end{tabular}

We should also note that obviously corrected, as the result of training, were such personality features as the readiness for adaptation and avoidance of conflict (see Table 6).

Table 6. The readiness for adaptation and avoidance of conflict before and after training

\begin{tabular}{lllllll}
\hline $\begin{array}{l}\text { Referential group before } \\
\text { training }\end{array}$ & $\begin{array}{l}\text { Referential } \\
\text { training }\end{array}$ & group & after & $\begin{array}{l}\text { Control group before } \\
\text { training }\end{array}$ & $\begin{array}{l}\text { Control group after } \\
\text { training }\end{array}$ & gup \\
\hline Adaptation & & & & & \\
7.2 & 7.9 & 7.0 & 7.2 \\
Avoidance of conflict & & & \\
10.1 & 6.4 & 9.2 & 9.1 \\
\hline
\end{tabular}


To examine the ability of a person to self-disclose in communication "the questionary for the level of self-disclosure" (modification of the questionary of Jourard S.) designed by Amyaga N.V. was used. The questionary includes ten topics, which are estimated on four-point scale. The estimation is performed in "points", where the resulting indicator can be in the range from 0 to 40 under the condition the higher the index, the higher the level of self-disclosure and, subsequently, the more personal information is communicated to other people and the more the person encourages other people for recognizing himself. The hypothesis suggested under the present method implied that as the result of training its participators should gain increased indicators of self-disclosure in communication.

As the result of statistical analysis under the present test there are no significant changes registered $(p=0.865773)$, what shows that, as the result of training, there were no changes in experimental group. The same situation holds true for the control group as well $(\mathrm{p}=0.128200)$.

If we conduct the qualitative analysis of table for experimental group (Table 7), we will see that in the cases of four students there is a reduction of the present indicator of 1-3 points, in the case of one more student it has remained the same, while in the cases of the rest of students in has increased 12 points. However, on the whole the indicators have remained at the average level.

Table 7. The results of pre- and post-testing in experimental group

\begin{tabular}{lcccccccc}
\hline No. & Sex & Age & QACSC & QACFCP & QLS & QACSC2 & QACFCP2 & QLS2 \\
\hline 1 & 1 & 17 & 10 & 25 & 16 & 10 & 27 & 15 \\
2 & 1 & 17 & 15 & 23 & 19 & 12 & 26 & 18 \\
3 & 1 & 18 & 13 & 23 & 17 & 8 & 27 & 34 \\
4 & 17 & 9 & 24 & 15 & 11 & 28 & 11 \\
5 & 1 & 17 & 15 & 34 & 24 & 16 & 32 & 33 \\
6 & 1 & 18 & 15 & 26 & 23 & 16 & 30 & 21 \\
7 & 0 & 18 & 21 & 29 & 23 & 19 & 32 & 23 \\
8 & 0 & 18 & 16 & 26 & 20 & 8 & 29 & 16 \\
9 & 1 & 17 & 16 & 26 & 20 & 17 & 34 & 21 \\
\hline
\end{tabular}

Sex: "1" - female; "0" - male;

QACSC - the questionary for the ability to control self-presentation in communication;

QACFCP - the questionary for the ability to cause the frankness of conversation partner;

QLS - the questionary for the level of self-disclosure (modification of the questionary of Jourard S.);

No index - the results of pre-testing;

Index "2" - the results of post-testing.

The analysis of table for the control group (Table 8) shows the indicator of five students has declined 2-6 points, while the indicator of the rest of students has increased 3-4 point. 
Table 8 . The results of pre- and post-testing in control group

\begin{tabular}{lcccccccc}
\hline No. & Sex & Age & QACSC3 & QACFCP3 & QLS3 & QACSC4 & QACFCP4 & QLS4 \\
\hline 1 & 0 & 17 & 22 & 29 & 21 & 13 & 27 & 15 \\
2 & 1 & 17 & 17 & 33 & 10 & 20 & 36 & 13 \\
3 & 0 & 18 & 11 & 23 & 15 & 14 & 32 & 9 \\
4 & 1 & 18 & 13 & 28 & 24 & 12 & 28 & 18 \\
5 & 1 & 17 & 15 & 24 & 19 & 21 & 23 & 13 \\
6 & 0 & 17 & 16 & 32 & 18 & 20 & 31 & 22 \\
7 & 1 & 18 & 19 & 38 & 26 & 17 & 34 & 24 \\
8 & 1 & 18 & 13 & 26 & 20 & 13 & 24 & 16 \\
9 & 1 & 18 & 14 & 25 & 14 & 12 & 32 & 12 \\
\hline
\end{tabular}

Sex: "1" - female; "0" - male;

QACSC - the questionary for the ability to control self-presentation in communication;

QACFCP - the questionary for the ability to cause the frankness of conversation partner;

QLS - the questionary for the level of self-disclosure (modification of the questionary of Jourard S.);

Index " 3 " - the results of pre-testing;

Index "4" - the results of post-testing.

Thus, we can conclude that although the statistical processing of the data shows no significant differences in the quizzes of experimental group, the observed differences in individual indicators of qualitative analysis say that after the impact there after all were some changes.

That is why we can suppose that significant differences, the effect of training impact on the present ability, can manifest after a while-when person will bring the suggested schemes to real life, in the connection with which there will be significant changes of personality defined with the development of the ability of self-disclosure.

To examine the ability to cause the frankness of conversation partner we have used "the questionary for the ability to cause the frankness of conversation partner" designed by Amyaga and containing ten topics, each of which is estimated on four-point scale. The higher the resulting indicator that can be in the range from 0 to 40 , the strongly marked the ability to cause the frankness of conversation partner.

Statistical analysis has also identified the significant tendency for development of the present ability $(\mathrm{p}=0.015161)$. In the control group there is no such tendency registered $(\mathrm{p}=0.916513)$.

The analysis of Tables 7 and 8 showed that the indicators on the present ability have increased 2-4 points in cases of eight participators of training and in the case of another one student the indicator has decreased 2 points. In the control group in cases of four students the indicator has decreased 1-4 points, in the case of another one student it has remained at the same level, and in the cases of two more students the indicator has increased 3 and 9 points.

All these witness the training had an impact on the ability of person to cause the frankness of conversation partner, as to the bigger degree it was focused on the development of personality in the area of "competence in partner" and on the realization of the effects of interpersonal perception and ways of communication with 
account of partner's modality.

It also can witness that in the process of training the shields preventing from organization of efficient process of communication were removed and the participators felt more self-confident. The atmosphere changed in the process of training promoted improvement of social-psychological climate that, in turn, promoted the development of active group emotional identification.

\section{Discussion and Conclusions}

According to the result of test of Thomas, in experimental group there was reliable reduction of predisposition to avoidance of conflict situations registered. Predisposition to adaptation as the form of resolving conflict situation in average has remained at the initial level, however the personal dynamics of such predisposition in number of cases was ambiguously changing.

To estimate the level of reliability of difference in two excerpts (before and after training course) we have used the well-known Student criterion within the frameworks of standard computer program called "Statistica". As the results of held diagnostic methods, observations and oral self-reports of training participators obtained in the process of reflexion, we can conclude that the procedure of group psychological training is being appropriate for optimization of the process of business and interpersonal communication between first-year students (the indicators of communicative and organizational skills of students have increased (at least, on the level of self-perception) Thus, according to COT-2, the communicative skills have increased from $4 \pm 0.7$ to $17.8 \pm 0.46$; organizational skills - from $9.7 \pm 0.82$ to $15.6 \pm 0.91$, i.e. by more than half).

- The organization of cooperation within the process of communication under new and more effective schemes will also promote more effective adaptation. The indicators of cooperation have increased from $5.4 \pm 0.64$ to $9.1 \pm 0.65$, of compromise- from $5.8 \pm 0.41$ to $9.7 \pm 0.62$.

- The increase of indicators of cohesion of collective will allow students more successfully to pass the period of social and psychological adaptation (cooperation, organizational skills).

- The conduction of the training in student collective reliably reduces the total level of conflicts as well as the pressure in the group (rivalry).

As the result of training, there is substitution of old interaction schemes (adaptation, avoidance) with new ones (cooperation, compromise) that allow optimizing the processes of communication. There also was removal of shields preventing from the process of communication and, subsequently, from slow adaptation. The pressure in the group has decreased, while the cohesion of the group has increased.

In such a way, according to the results of research and analytical data listed in the paper, we can say that the developed and approved program of the training is being appropriate for optimization of business communication in a group and, subsequently, for increase of cohesion of collective, improvement of mutual understanding and increase of efficiency of mutual activities, what promotes more successful social-psychological adaptation of graduates and students and reveals significant prospects for further researches in this direction.

The conducted training has significant impact on increase of cohesion of collective, reduction of level of conflicts, improvement of cooperation and predisposition to result. This makes us consider that the process of social-psychological adaptation for students of Crimea and Sevastopol will be painless to the uttermost.

\section{References}

Abulkhanova-Slavskaya, K. A. (1981). Development of personality in the process of life activities. In Psychology of formation and development of personality. Moscow.

Ball, G. A. (1989). The term of adaptation and its significance for psychology of personality. Matters of Psychology, 1.

Berezhnaya, M. S. (2013). The system of criteria for estimation of person's creativity in art activity in the system of education. The problems of creative development of personality in the system of school education. In A. V. Krinitsina (Ed.), Collection of scientific articles on the materials of research and practice seminar held on February 19, 2013 in Moscow. Moscow: IAE RAE.

Berezhnaya, M. S. (2014). Abilities and talents management in the process of formation of creative intellectual educational environment. Management sciences in modern Russia: Collection of reports of scientific conference, 1, 396-404. 
Bezuleva, G. V. (2008). Psychological and pedagogical maintenance for professional adaptations of learners and students. In Monography (p. 320). Moscow: NSEE HPE Moscow psychological and social institute.

Dikaya, L. G., \& Zhuravlev, A. L. (2007). Psychology of adaptation and social environment: Modern approaches, problems, prospects. Moscow.

Kantor, V. Z. (2004). Pedagogical rehabilitation and style of blind and starblind. Saint Petersburg: Karo.

Kazanskaya, V. (2011). Teenager: Social adaptation. Saint Petersburg.

Khitskaya, V. Y. (2008). Account of cognitive styles as the mean of adaptation of first-year students to education in university. In Monography (p. 128). Irkutsk: Irkutsk University.

Milkovskaya, I. Y. (2007). Pedagogical conditions for adaptation of first-year students in the educational process of higher school. Volgograd: Edition of State University of Volgograd.

Mischel, W. (1984). Introduction to Personality. New York.

Nachaldjyan, A. A. (1988). Social-psychological adaptation of a person. Erevan.

Parygin, B. D. (1971). Basics of social-psychological theory. Moscow.

Pozharskaya, E. L., \& Deberdeeva, N. A. (2013). Innovative activity of HEI in applying and development of modern technologies of education. In Materials of the X International scientific and practical conference. Moscow: Tula, Tula Institute of Economy and Informatics.

Pozharskaya, E. L., \& Deberdeeva, N. A. (2013). Professional self-conception of young people in the process of socialization. Collection of scientific articles on the materials of research and practical seminar held on.

Pozharskaya, E. L., \& Deberdeeva, N. A. (2014). Corporate education as the basis for formation of intellectual capital of organization. International scientific conference "Actual problems of development of education in Russia and abroad.

Pozharskaya, E. L., \& Deberdeeva, N. A. (2014). Self-conception of a person as the factor of personal and professional development (pp. 84-89). Materials of the XInternational scientific and practical conference "Trends of modern science" held in 2014.

Rean, A. A. (1991). About the phenomenon of social-psychological tolerance of a person. Psychological journal, 4, 181-182.

Rean, A. A. (1995). Concerning the problem of person's social adaptation. Vestnik, 3(20), 74-79.

Rean, A. A. (1997). Concept of locus of control and the problem of personal maturity (pp. 367-375). Theoretical and applied matters of psychology: The materials of anniversary conference "Ananievskie readings 97".

Rean, A. A., \& Kolominsky, Y. L. (1999). Social pedagogical psychology (p. 416). Saint Petersburg.

Vachkov, I. V. (2000). The basics of group training technology. In Psychotechniques: Study guide (2nd ed., p. 224). Moscow: Publishing house "Os'-89".

Vasyakin, B. S., \& Pozharskaya, E. L. (2014). Modern technologies of professional education. Materials of international scientific conference "Theory and methods of professional education".

\section{Copyrights}

Copyright for this article is retained by the author(s), with first publication rights granted to the journal. This is an open-access article distributed under the terms and conditions of the Creative Commons Attribution license (http://creativecommons.org/licenses/by/3.0/). 